\title{
PROJETO DE CAPTAÇÃO DE CÓRNEAS PARA TRANSPLANTES: EXPERIÊNCIA EM UM HOSPITAL GERAL
}

\author{
Project of Corneas Harvesting for Transplantation: Experience of a General Hospital
}

\author{
Otto Cezar Barbosa Júnior1, Cristiane Pereira Pedro Garcia², Márcia Floro da Silva ${ }^{3}$
}

\begin{abstract}
RESUMO
Racional: Este trabalho pretende apresentar os resultados do Projeto Luz, que visa captar córneas para transplante, em um ano de funcionamento. Composto por 32 voluntários, em esquema de revezamento contínuo, o projeto conta com um plantão a distância, permanente de 24 horas. Essa equipe entra em ação somente quando solicitada a fim de fazer contato com a família para a captação de córneas de pacientes que vão a óbito com idade superior a dois anos. Método: As abordagens são registradas em documentação específica da Comissão Intra-Hospitalar de Transplantes para posterior análise, controle e registro legal. De acordo com os dados, foi feito um estudo em que se realizou uma contagem frequencial retrospectiva desses registros seguida de cálculo percentual. Resultado: Durante um ano de atividades do projeto, houve 725 contatos dentre os quais 367 foram positivos. Efetivaram-se, assim, 734 unidades de córneas captadas, representando um total de 50,6\% de consentimentos familiares à doação. Conclusão: Partindo-se do pressuposto de que, no momento em que a família é avisada sobre o óbito, nem sempre está preparada para a doação espontânea, esse trabalho mostra-se extremamente relevante e eficaz. Apesar dos constantes incentivos do Ministério da Saúde por meio de campanhas de esclarecimento e políticas de maior investimentos no setor de transplantes e captações, o número de pacientes na fila de espera ainda é alto. Considerando os resultados do Projeto Luz, percebe-se a importância, além das campanhas de conscientização, da implementação de projetos similares nos centros de saúde que visem diminuir o tamanho desta fila.
\end{abstract}

Descritores: captação de órgãos, córneas, transplante, abordagem familiar, hospital.

Trabalho realizado na Fundação Civil Casa de Misericórdia de Franca - Franca-SP Comissão Intra-Hospitalar de Doação de Órgãos e Tecidos para Transplantes da Santa Casa de Franca

1. Médico urologista e presidente da Comissão Intra-Hospitalar de Doação de Órgãos e Tecidos para Transplantes da Santa Casa de Franca.

2. Mestre em psicologia pela Universidade de São Paulo e psicóloga da Comissão IntraHospitalar de Doação de Órgãos e Tecidos para Transplantes da Santa Casa de Franca.

3. Especialista em administração dos serviços de saúde pela Unaerp, membro do núcleo de pesquisa Quavisss da Unesp-Franca e assistente social da Comissão Intra-Hospitalar Doação de Órgãos e Tecidos para Transplantes da Santa Casa de Franca.

Endereço para correspondência: Otto Cézar Barbosa Júnior - Rua Abelardo Domenes Rúbio, 490, apto 21-b - CEP: 14401-261 - Franca-SP - Fone: (16) 3721-1010 - e-mail cristianepedro@bol.com.br

Recebido em: 13/06/05

Aceito em: 05/07/05

\section{INTRODUÇÃO}

O transplante de córnea constitui opção terapêutica viável para grande parte das doenças causadas pelo seu comprometimento.

Observa-se que os avanços constantes nas técnicas, no processamento dos órgãos, na avaliação e conservação das córneas têm propiciado um aumento considerável no número de cirurgias, bem como uma melhora importante nos resultados pós-operatórios. Por essa razão, esse tipo de transplante ganhou a posição de líder em um número de procedimentos entre os de órgãos e tecidos em geral. ${ }^{1}$

Porém, o número de cirurgias realizadas, na maioria dos serviços é ainda pequeno em relação à demanda de pacientes à espera desse tratamento., ${ }^{1,2}$

No Brasil, o Ministério da Saúde divulgou, no mês de maio de 2005 , que havia cerca de 25.178 pessoas aguardando um transplante corneano, número só suplantado pela fila de rim. ${ }^{2}$

Diversamente de outros órgãos do corpo humano, as córneas podem ser retiradas, com êxito, até seis horas após a parada da atividade cardiovascular do doador.

Conforme a legislação atual vigente no país, qualquer retirada de órgãos ou tecidos deve ser previamente autorizada pelos familiares. Portanto, na medida em que aumentam a sua disposição em doá-los. Contudo, na hora da morte, nota-se que mesmo com o consentimento da família, não existe um sistema eficaz para realizar a captação. ${ }^{3}$ 
Com base nessa premissa, a Comissão Intra - Hospitalar de Transplantes da Santa Casa de Franca criou o Projeto Luz que teve início no mês de julho de 2003. Seu objetivo é captar córneas, para fins de transplantes, através da abordagem e obtenção da autorização dos familiares dos doadores que tiveram morte com coração parado na instituição.

A equipe responsável é formada por voluntários advindos dos clubes de serviço da comunidade, bem como de outras entidades filantrópicas sem fins lucrativos. Todos os que dela participam passaram previamente por um rigoroso treinamento ministrado por especialistas que garante, assim, a eficácia dos serviços prestados.

Constatada a morte de um de seus pacientes, a Santa Casa e Hospital do Coração de Franca comunicam o ocorrido à equipe. Os 32 voluntários previamente definidos como plantonistas, ficam de prontidão nas 24 horas. São eles que se encarregam, da melhor forma possível, de fazer a abordagem familiar.

Esse projeto foi submetido a uma avaliação que teve como finalidade apontar os seus resultados iniciais.

\section{MÉTODO}

Realizou-se um estudo dos registros de abordagem familiar para captação de córneas ocorridos no período de 22 a 31 de julho de 2004. Os dados foram analisados de maneira quantitativodescritiva, apresentados em freqüência seguidos do cálculo de porcentagem.

\section{RESULTADO}

O número dessas abordagens, realizadas durante o período mencionado, foi distribuídas da seguinte forma, conforme mostra a tabela 1:

Tabela 1. Abordagens realizadas de julho de 2003 a julho de 2004

\begin{tabular}{|c|c|c|c|c|c|}
\hline \multirow{2}{*}{ Mês } & \multicolumn{2}{|c|}{ Abordagem positiva } & \multicolumn{2}{c|}{ Abordagem negativa } & $\begin{array}{c}\text { Número de } \\
\text { abordagens }\end{array}$ \\
\cline { 2 - 6 } & $\mathrm{n}$ & $\%$ & $\mathrm{n}$ & $\%$ & $\mathrm{n}$ \\
\hline 01 & 48 & 50,5 & 47 & 49,5 & 95 \\
\hline 02 & 36 & 53,7 & 31 & 46,3 & 67 \\
\hline 03 & 18 & 40,9 & 26 & 59,1 & 44 \\
\hline 04 & 31 & 50 & 31 & 50 & 62 \\
\hline 05 & 29 & 60,4 & 19 & 39,6 & 48 \\
\hline 06 & 26 & 46,4 & 30 & 53,6 & 56 \\
\hline 07 & 43 & 56,6 & 33 & 43,4 & 76 \\
\hline 08 & 28 & 43,8 & 36 & 56,2 & 64 \\
\hline 09 & 23 & 47,9 & 25 & 52,1 & 48 \\
\hline 10 & 26 & 44,1 & 33 & 55,9 & 59 \\
\hline 11 & 28 & 54,9 & 23 & 45,1 & 51 \\
\hline 12 & 31 & 58,5 & 22 & 41,5 & 53 \\
\hline Total & 367 & 50,8 & 356 & 49,2 & 723 \\
\hline
\end{tabular}

Fonte: Fundação Civil Casa de Misericórdia de Franca 2003 e 2004. Legenda: $\boldsymbol{n}$ - número $\%$ - porcentagem
Dos 723 óbitos ocorridos no complexo Fundação Civil Casa de Misericórdia de Franca que poderiam ser doadores potenciais de córneas, 367 efetivaram a doação. Portanto, o percentual de abordagens positivas, nos primeiros doze meses do Projeto Luz, foi de $50,8 \%$.

Se considerarmos que cada um dos 367 representa duas captações de córneas, o projeto conseguiu, nesse curto período de funcionamento, um total de 734 unidades desse órgão, com uma média de $61 /$ mês e, conseqüentemente, 2,03/dia. É um resultado bastante significativo.

\section{DISCUSSÃO}

Analisando os dados, retrospectivamente, pôde-se observar que a média de 50,8\% que se obteve na Fundação Civil Casa de Misericórdia de Franca é alta se comparada com os da Central Estadual de Transplantes para captação de múltiplos órgãos que é de $22,5 \%{ }^{4}$

No mês de março, houve um decréscimo no percentual de abordagem familiar positiva, que variou 10 pontos percentuais na média. O motivo foi uma restrição na idade do doador (menos de 65 anos) devido a dificuldades de locomoção da equipe que realizava a enucleação de córneas.

Uma hipótese levantada com tal fato é que o aumento da idade do doador pode ter uma correlação com a predisposição da família em autorizar a doação. Entretanto, uma investigação mais detalhada precisa ser realizada para confirmá-la ou não.

Antes do Projeto Luz, a captação de córneas realizadas na Santa Casa de Franca era de aproximadamente dez por ano. Logo, houve um aumento considerável nesse número.

Enquanto todo estado do Rio Grande do Sul captou em média, em 2003, 65,7 córneas/mês, o Projeto Luz conseguiu 61 no mesmo período. Com esse resultado, ele representou $14 \%$ da demanda do estado de São Paulo em cuja fila havia 5.250 pessoas aguardando por um transplante em julho desse mesmo ano. ${ }^{5}$

O saldo positivo, sem dúvida, está relacionado com processo da abordagem familiar que compreende três aspectos importantes: o momento, o local e a maneira como é realizada.

Quando a família perde um ente querido, os sentimentos que acompanham essa perda são dos mais profundos, mais intensos, multifacetados. Mesmo que ela seja favorável à doação de órgãos, ou não se lembra de fazê-la, ou ainda que queira tomar essa atitude, desconhece os procedimentos que deve seguir para que seu desejo seja concretizado. Daí a importância de que dentro dos hospitais, onde ocorre o maior número de óbitos, haja pessoas preparadas não só para fazer o contato com a família mas também que essa ação seja feita de forma adequada para, conseqüentemente, ser bem-sucedida.

Outro fator que pode ter contribuído para o êxito desse projeto: a família foi abordada em um ambiente tranqüilo e resguardado, onde pôde expressar seu sofrimento, tendo a sua privacidade assegurada. Isso fez com que os familiares se sentissem acolhidos e tivessem condições de ouvir sobre a possibilidade de atenderem positivamente ao apelo da equipe.

Outro aspecto relevante, nesse momento, foi a maneira como esse contato se realizou. O responsável pela abordagem esperou a hora em que o familiar estivesse em condições emocionais de "ouvir". 
Se estivesse chorando demasiadamente, negando a morte do ente, por exemplo, foi esperado até que ele se acalmasse. É evidente que se o indivíduo não está pronto para "ouvir", torna-se mais provável a negação ou recusa do pedido.

Possuir uma formação técnica e ser capaz de responder às dúvidas dos familiares foram fundamentais, pois questões como “ele usava óculos", "tinha catarata”, "não enxergava bem” foram freqüentemente apresentadas à equipe. Fornecer informações sobre a demanda de córnea existente, tempo necessário para a sua retirada, reconstituição física do doador, bem como esclarecer dúvidas dos familiares podem ajudar no processo de decisão.

Nesse momento delicado, de muita consternação, tornou-se importante também auxiliar a família para relembrar o desejo, em vida, do possível doador. Além disso, é preciso considerar que cada um precisa de um tempo específico para tomar essa decisão. Respeitar este tempo, isto é, não forçando qualquer decisão precipitada, faz com que ela se sinta igualmente respeitada.

Vale ressaltar que não é função da pessoa responsável pela abordagem convencer a família pela doação, e sim, ajudar que ela tome tal decisão. Assim, qualquer que seja a resposta dos familiares, ela deve ser compreendida e acatada.

\section{CONCLUSÃO}

Com esses dados, podemos concluir que, mesmo sendo a família favorável ao processo de doação de órgãos, é necessário um sistema efetivo de abordagem, autorização e realização da enucleação.

Para que as chances de uma resposta positiva, por parte da família, aumentem, é preciso reiterar os aspectos fundamentais já discutidos: o momento da abordagem, que deve ocorrer próximo à notícia do óbito; o local, que deve ser tranqüilo, garantindo privacidade e sigilo; a maneira como é abordada, considerando a hora apropriada e a possibilidade de oferecer as informações necessárias para facilitar o processo, sempre respeitando a sua decisão por ser soberana.

\section{AGRADECIMENTOS}

Aos voluntários do Projeto Luz e familiares de doadores que tornaram viável este projeto.

À revisão de texto. Prof ${ }^{a}$ Maria Helena de Castro Paganucci Criar - sistema de ensino de língua portuguesa

www. cursocriar.com

Translated by Eliane Querino

\section{ABSTRACT}

Objective: The aim of this study was to present the results of the "Light Project" which had as main purpose to obtain corneas. The project was composed by 32 volunteers working in continuous 24-hours at distant relay that only gets in action upon request, in order to get in touch with the relatives to obtain corneas from donors. Methods: The approaches are registered in specific documentation, in order to further analyze, control and legally register the donation. According to the data, a study has been carried out performing a retrospective counting of the frequency of these registers, and next, calculating the percentage. Results: During the one year period of activities of such project, there had been 725 contacts, 367 of which proven to be positive. Therefore, 734 corneas had been obtained, representing $50.6 \%$ of the amount of permissions to the donation. Conclusion: Taking into account that at the moment the family receives the report of death they are not always prepared to grant the donation, this kind of work appears to be extremely relevant and effective. Considering the results of the "Light Project", it can be only figured out the importance to implant similar projects in health centers, added to clarifying campaigns, in order to lessen the extent of the waiting lists.

Keywords: transplant, statistics, cornea captivation, donation, hospital.

\section{REFERÊNCIAS}

1. Rodrigues A M, Sato E H. Conhecimento e atitude do Hospital São Paulo sobre doação de córneas. Arq Bras Oftalmol 2002;65:637-40.

2. www.saúde.gov.br
3. Sousa S J F, Baretto S. Entrevista da família para obtenção de órgãos e tecidos para transplante. Arqu Bras Oftalmol 2003;66: p- .Suplemento

4. www.abto.org.br

5. www.bemcertinho.com.br 